\title{
MÍDIA E JUVENTUDE: EXPERIÊNCIAS DO PÚBLICO E DO PRIVADO NA CULTURA
}

\author{
Rosa Maria Bueno Fischer ${ }^{*}$
}

RESUMO: Discuto resultados de pesquisa com grupos de jovens, sobre sua experiência com a mídia, relativamente aos modos pelos quais nossa cultura vem construindo a ação e a expressão da vida pública e da vida privada. Faço uma análise tanto de produtos televisivos destinados a esse público, como do "texto" produzido nos debates com os grupos de recepção, a respeito de como se caracterizaria, hoje, para esses jovens, o "agir humano", a vida em comum, as trocas e a convivência entre os "diferentes". A análise articula conceitos como os de poder e subjetivação em Foucault, sociedade individualizada em Zygmunt Bauman, com a proposta de Hannah Arendt sobre o agir humano e sua problematização quanto às esferas pública e privada. Proponho possíveis estratégias para a escola, com o fim de produzir pensamento sobre as imagens com que interagimos e a incentivar modos solidários de convivência.

Palavras-chave: Mídia. Juventude. Esfera pública. Esfera privada.

MEDIA AND YOUTH: PUBLIC AND PRIVATE EXPERIENCES ON CULTURE

ABSTRACT: I discuss results from research done with youth groups, about their experience with the media, regarding the ways on which our culture has been building the action and expression of public and private life. I analyse not only television "products" made for this public sphere, but also the "text" produced in discussion groups, regarding the way they would characterize today, for these youths, the "human conduct", the ordinary life, the changes and acquaintanceship among the "different ones". The analysis articulates concepts such as Foucault's power and subjectivity,

Doutora em educação e professora da Universidade Federal do Rio Grande do Sul (UfRGS).

E-mail: rosamar@plug-in.com.br 
Mídia e juventude: experiências do público e do privado na cultura

Zygmunt Bauman's individualized society, with Hanna Arendt's proposal on human conduct and his problematic regarding the public and private spheres. I propose possible strategies for the school, in order to produce a thought over images with which we interact and motivate reciprocal ways of acquaintanceship.

Key words: Media. Youth. Public sphere. Private sphere.

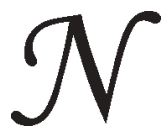

este artigo, discuto sintomas da cultura contemporânea, relativos aos modos pelos quais adolescentes e jovens, de diferentes extratos sociais, vêm sendo formados cotidianamente, com a participação dos meios de comunicação, em especial a televisão. Tendo como base dados de pesquisa recente com grupos de estudantes de 15 a 25 anos, ${ }^{1}$ e orientada por autores como Michel Foucault, Hannah Arendt, Zygmunt Bauman e Slovaj Zizek, procuro estabelecer um debate sobre a tendência crescente que experimentamos de publicizar a vida privada e expor a intimidade nos espaços públicos, as implicaçóes no que se refere à produção de novas subjetividades e às formas como estamos efetivando uma aprendizagem sobre os outros, as diferenças políticas e sociais; igualmente, trato daquilo que vimos aprendendo sobre o que é da ordem do público e do privado; ainda, sobre os sentidos e as atitudes com relação ao que chamamos de real e de virtual.

Considerando que desde o início dos anos de 1990 há investimentos intensos em endereçar uma gama variada de produtos ao público jovem (pré-adolescente, adolescente e propriamente jovem), temos não só buscado analisar alguns desses materiais como também, nas últimas investigaçôes, dedicamo-nos a escutar esses mesmos grupos. ${ }^{2} \mathrm{O}$ objetivo é mostrar como a mídia delineia, situa, sugere e estimula determinadas formas de existência coletiva ou de relação consigo mesmo e com o outro, em suas criações para jovens; ao mesmo tempo, examinar esses mesmos produtos com grupos de estudantes de ensino médio de escolas públicas e particulares e alunos de dois cursos de uma universidade pública.

Temos como pressuposto, a partir de Hannah Arendt (2000), que o público - e, portanto, o político - só pode ser pensado como ação, como ação performativa, agonística, como acontecimento, como irrupção; enfim, como interrupção de todos os processos automatizados, totalizantes. Ora, como pensar o político hoje, dentro dessa proposta de 
Arendt, se nossas atuais concepçôes e práticas de democracia, de pluralidade, de vida em comum aparecem pari passu com a associação da política à corrupção, em que a propaganda e o marketing político assumem um caráter de exposição contínua da privacidade dos governantes e dos candidatos a cargos públicos? Como pensar em práticas coletivas de existência, se a ordem é a competitividade acirrada, generalizada, a qual, por sua vez, coloca no centro a disputa pelo corpo mais belo, mais jovem e mais "trabalhado"? Como incentivar o olhar generoso sobre o outro, a escuta do outro, quando todo o investimento se faz no sentido de apresentar aquilo que é da ordem do público como um fardo indesejável?

Para Arendt, o terror dos regimes totalitários foi (e é) responsável por aniquilar a individualidade humana, a espontaneidade dos sujeitos individuais e dos grupos, enfim, a criativa ação humana, justamente por apostar no Grande Homem, numa espécie de coletivo que acaba por cingir a pluralidade, dissolvendo-a numa imensa massa informe, característica também desta sociedade, batizada de sociedade da informação ou sociedade do conhecimento - que Bauman (2001) chama de sociedade individualizada. Libertos dos obstáculos físicos, em virtude das novas tecnologias de informação e comunicação, muitos de nós - mas não todos nós - podemos nos apropriar de um mundo fantástico de imagens, dados, sons; temos um poder que não é deste mundo, como escreve Bauman, um poder desencarnado, que nos confere uma capacidade imensa de nos movermos e de atuarmos a distância. Ao mesmo tempo, muitos outros - e são seguramente muitos, quantitativamente, num país como o Brasil - acompanham literalmente a distância essa mesma possibilidade de liberdade de movimentos no reino do virtual, com uma perda que não podemos desconsiderar: as localidades às quais essa grande maioria se vê confinada, justamente pela força da outra realidade maior, do mundo on-line, são realidades que gradativamente perdem força e vitalidade, passam a carecer de importância.

Tudo indica que a TV aberta continua a ser, ainda hoje, a grande fonte de lazer e informação para a maioria da população. Ela certamente oferece uma janela para o mundo, uma possibilidade de acesso a informaçôes imediatas sobre acontecimentos de diferentes pontos do planeta. Ao mesmo tempo, porém, esse meio de comunicação ensina algo que muitos depoimentos dos grupos de jovens confirmaram: vidas privadas e intimidades invadem o cenário público da mídia não exatamente para que haja uma interação com os espectadores, para in- 
Mídia e juventude: experiências do público e do privado na cultura

troduzir uma nova discussão com relação aos modos de existência do público e do privado em nossa sociedade. Como assinala Bauman, no máximo o que se faz é fortalecer o privado em sua privacidade (ibid., p. 231). Programas televisivos sobre a intimidade das pessoas, sejam elas célebres ou não,

(...) são lições públicas sobre a vacuidade da vida pública e sobre o vazio das esperanças postas em tudo o que seja menos privado que os problemas e as soluçôes particulares. Os solitários indivíduos entram hoje numa ágora e não se encontram a não ser com outros que estão tão sós como eles mesmos. Voltam para casa tranqüilizados com sua solidão reforçada. (Bauman, 2001, p. 231; tradução minha e grifo do autor)

Aprendemos a falar das instituições públicas como cada vez mais impotentes: diminui significativamente o atrativo por temas que sejam de interesse comum; parece que reduzimos em nós a capacidade e a própria vontade de trazer os sofrimentos privados para o lugar da discussão de questões públicas: vamos internalizando um modo peculiar de olhar e tratar "a dor dos outros", como refere a pensadora Susan Sontag em recente livro (2003).

Para a TV brasileira, seja em suas peças sensacionalistas como Programa do Ratinho, Domingo Legal, Linha Direta, ${ }^{3}$ entre tantos outros, seja em suas telenovelas ou minisséries, seja ainda em seus materiais jornalísticos, como tão bem sintetiza a estudiosa Ivana Bentes,

(...) o que parece estar em questão é o imediatismo do espetáculo e no máximo a satisfação individual, mais que uma política do comum, ampla, constituinte e democratizante. A idéia de uma cidadania pela mídia - com prestação de serviços, informações de interesse coletivo, formação de "redes" de auxílio material, psicológico, emocional etc. - por enquanto é a face de um incipiente populismo de mercado, mas que guarda uma potência de transformação. (Bentes, 2003, p. 5)

\section{Comércio dos sentidos}

Estamos falando aqui da mídia, e particularmente da TV, como um espaço fundamental, em nossa sociedade, de responder àquilo que Bauman chama de "estratégias de transcendência": somos seres colocados diante da possibilidade (e da consciência) de nossa morte. Desde sempre, procura- 
mos de alguma forma inventar estratégias de transcender essa realidade, literalmente de "aprender a morrer". Ora, num tempo de infinitas possibilidades de produção e especialmente de veiculação e circulação de sons, imagens, textos, ocorre que participamos de um dos mais competitivos mercados - o comércio dos sentidos. Filmes, programas de TV, narrativas de todos os tipos, em revistas, livros, jornais, pinturas e esculturas, peças de teatro, páginas na internet - tudo isso existe, cria-se, multiplica-se, cada vez mais, a partir dessa necessidade básica de ultrapassar nossas contingências. De acordo com Bauman, essa é uma realidade que se fixa, com poucas perspectivas de reduzir-se em curto e em longo prazos: é improvável que a utilidade (mesmo que marginal) dessas mercadorias se reduza, bem como é improvável que a demanda impulsionadora dessa oferta competitiva se esgote (Cf. Bauman, 2001, p. 14).

Importa é saber como esse comércio de sentidos está chegando às pessoas, que tipo de produtos estão sendo ofertados, como os diferentes grupos vivenciam essa realidade proposta nos artefatos culturais, como se posicionam diante dela, e a que papel a escola estaria sendo convocada, quando, por exemplo, seus alunos referem que podem ficar até seis horas diárias diante da TV - como ocorreu em vários depoimentos dos grupos de recepção. A análise dos produtos televisivos ${ }^{4}$ tem mostrado que, neles, valorizar a vida privada não só corresponde à exacerbação do individualismo como expõe a grande divisão e até oposição entre a esfera privada, de um lado, e as esferas social e política, de outro.

Hannah Arendt já nos alertou para a impossibilidade real de comunicarmos por completo o que é da ordem do íntimo - como ocorre com o sentimento profundo e genuíno da solidão. Mas o curioso é que em nossa sociedade alimentamos todos os dias a necessidade de sermos ouvidos e vistos no espaço público (da mídia), já que isso nos garantiria uma espécie de realidade (Cf. Arendt, 2000, p. 60). Para a filósofa que escreveu essas reflexões nos anos 50 do século passado -, a ampliação da esfera privada não a transforma em pública, pelo contrário, significa que a própria esfera pública refluiu. Ainda: estar na companhia dos outros parece ter perdido força, já que ficamos cada vez mais privados de ver e ouvir profundamente os outros, prisioneiros que nos tornamos de nossas subjetividades.

Vidas vividas e vidas narradas (no caso, narradas no espaço midiático) estão em íntima relação. Estudar a mídia e as vidas narradas, e ir 
Mídia e juventude: experiências do público e do privado na cultura

atrás das vidas vividas e do que elas têm a dizer sobre como são narradas é uma das tarefas principais da pesquisa aqui discutida. Vidas narradas e vidas vividas estão inter-relacionadas e são interdependentes. Códigos sociais e culturais, visíveis e vividos no interior dos diferentes espaços sociais constituem, pautam, normalizam e normatizam não só a própria criação, a elaboração das narrativas, como ainda o modo pelo qual elas são lidas, percebidas, recebidas.

Ocorre que a produção das narrativas e simultaneamente dos sujeitos não sucede de modo mecânico e unívoco: analisando produtos da mídia e depoimentos de grupos de jovens estudantes, vimos o quanto é possível descrever a complexidade dos sujeitos e das próprias narrativas midiáticas. Assim, nosso trabalho tem permitido mostrar linhas de força que regem a construção, por exemplo, de uma telenovela adolescente, como Malhação, veiculada há quase dez anos pela Rede Globo, de segunda a sexta-feira - programa que reitera o quanto adolescente é um ser de classe média, que se reduz a sexo, a escolhas amorosas, a escola, a conflitos familiares, o quanto também a mídia está ali, autopropondo-se como meio predominantemente educativo, pedagógico e didático.

É possível também observar, nos debates com jovens espectadores do programa Malhação, o quanto se cria um conjunto de estratégias de acolhimento desse público, formas de identificação, mesmo quando se trata de espectadores cujo perfil, a priori, não se enquadraria nos tipos humanos ali narrados. Meninas e meninos de classes populares afirmam identificar-se com os personagens de Malhação porque, como diz uma aluna, "eles também passam por dificuldades, que a maioria dos adultos acha que é besteira, mas que a gente passa também"; outra complementa, agora se referindo à novela Mulheres apaixonadas: 5 a TV fala de drogas, fala de "duas pessoas que gostam do mesmo sexo".

Ou seja, a TV mistura uma boa dose de não-verossimilhança (em Malhação, um dos episódios mostrou um personagem pedindo licença ao pai para ter sua primeira relação sexual) a aspectos amplamente passíveis de identificação, como os que se referem ao desejo de amar e ser amado, ao medo da traição, aos conflitos de gerações, ao grande segredo do sexo, entre outros. Ora, são esses elementos os que contam na elaboração das tramas novelescas, entrelaçados a valores, prescriçōes, opiniōes, que certamente carregam a marca de opções políticas, ideológicas, econômicas, assumidas pelo roteirista, pelo diretor, pela emissora, numa certa 
época. Importa é que esses produtos tematizam de alguma forma a juventude brasileira, falam com ela, dirigem-se a ela, buscam-na avidamente na condição de público consumidor e posicionam-se como lugar de educação e formação das gerações mais novas.

Conscientemente ou não, teremos na TV, nas revistas de ampla divulgação, nos programas de rádio, um lugar de aprendizado a respeito de nós mesmos, da vida que levamos, um aprendizado de como vamos receber e ler, pessoas classificadas para nós como heróis ou vilóes, cidadãos corretos ou como transgressores da ordem. Isso também ocorre com os personagens narrados no cinema, nos romances, nos livros de autoajuda, nos próprios materiais didáticos escolares. Interessa-nos indagar: como estamos aprendendo o sentido da vida pública em nossos tempos, por intermédio da mídia que consumimos? Bauman responde: estamos aprendendo que esta é, sobretudo, uma "sociedade dos indivíduos". Numa sociedade assim, o bem ou o mal que produzimos ou que sofremos parece que se deve exclusivamente a nós, a cada um de nós. É esse axioma que conduz as narrativas das vidas na TV.

Atores diariamente contam, em publicações jornalísticas sobre TV e em programas como Video Show, ${ }^{6}$ que chegaram à fama "meio que por acaso", "por sorte", "sem querer", foi para eles algo que "simplesmente aconteceu". São textos de atores, pessoas "reais", mas que fazem parte também dos diálogos dos personagens de novelas ou mesmo das histórias fantásticas dos programas vespertinos de todos os canais abertos, e ainda das enunciaçôes de homens e mulheres entrevistados em telejornais diários. Os fatos quase sempre aparecem isolados de uma história, de um panorama relacional, envolvendo condiçôes econômicas, sociais, culturais, geracionais, étnicas, e assim por diante. Um incêndio ou um desmoronamento num casebre quase sempre será narrado como fatalidade e como ocorrência única, individual, por vezes encerrados com um patético "Deus quis assim". Tudo aparece como imponderável, tudo foge à explicação mais complexa, aquela que se refere a algo para além da sorte ou do azar e da limitada experiência atomizada de indivíduos. Recorrendo mais uma vez a Bauman:

O traço caractertístico das histórias narradas em nossa época é que articulam as vidas individuais de uma maneira que exclui ou oculta a possibilidade de localizar os enlaces que vinculam o destino individual aos modos e maneiras mediante os quais funciona a sociedade em seu conjunto; mais 
Mídia e juventude: experiências do público e do privado na cultura

ainda, exclui o questionamento desses modos e maneiras, relegando-os a um segundo plano, não examinado, das ocupaçôes da vida individual, e os apresenta como "fatos brutos", matéria bruta que o narrador da história não pode colocar em dúvida nem negociar, seja um a um, seja num conjunto, seja coletivamente. (Bauman, 2001, p. 20; tradução minha)

Bauman ajuda-nos a pensar este tempo em que somos chamados a nos narrar, compulsivamente, a revelar nossas emoções e sentimentos, nossas sensações, nossas experiências pessoais e privadas. A TV é pródiga em exemplos desse tipo. Mas, pergunta-se Bauman, que tipo de reflexão acompanha essas narrativas? Para o pensador, falta algo fundamental: pensar as regras do jogo no interior das quais acontecem essas narrativas. Os debates com os grupos de recepção tiveram exatamente essa finalidade - fazer a escuta de estudantes, jovens de 15 a 25 anos, a partir da exibição de programas endereçados a esse público (como Malhação - da Globo, Tome conta do Brasil - da MTV) ou que porventura viessem a tratar da vida dos jovens brasileiros (no caso, a telenovela Mulheres apaixonadas, os telejornais Hoje e Jornal Nacional, Big Brother Brasil, a minissérie Cidade dos homens - todos da Rede Globo).

As discussões, todas gravadas em vídeo, propiciaram aos estudantes (e igualmente à equipe da pesquisa) um momento singular, de exposição das regras do jogo da mídia e de múltiplas possibilidades de entendimento das imagens, dos textos e dos sons veiculados. Durante os debates, aos poucos era possível mostrar para o grupo o quanto aquilo que pensamos, aquilo pelo qual somos julgados no meio social - tudo isso está em jogo na mídia - circula nos programas de TV, de tal forma que se poderia falar de uma homologia entre a lógica da publicidade, do mercado, dos meios de comunicação e das próprias práticas dos adolescentes e jovens pesquisados.

Uma reportagem do telejornal $H_{o j e} e^{8}$ - que apresentou em 2003 uma série de ediçôes com blocos exclusivamente sobre questôes envolvendo jovens -, no caso, a respeito de como os teens se relacionam com o dinheiro e o consumo, conduziu a discussão em que alunos de uma escola particular (do segundo ano do ensino médio) questionaram a afirmação feita na TV de que alguém pode ser excluído "só porque não tem dinheiro". Mas eles acabaram por confirmar a lógica maior: naquele ambiente de classe média, não usar um tênis de marca é na certa uma porta aberta para a exclusão, no mínimo para a crítica e o olhar diminuidor do outro. Um dos adolescentes brincou com a própria convicção de que, não 
atendendo às regras de consumo e de imagem, certamente se arriscaria a ouvir uma frase como esta: "Cara, esse teu tênis é de camelô...". Essa mesma turma de alunos viu-se cair seguidas vezes em contradições quanto a uma suposta abertura com relação ao outro que é diferente da norma, ou às próprias certezas sobre respeito às opçóes sexuais de quem quer que seja. No debate, listaram - em meio a risadas e ao apoio geral da turma quanto à "necessidade" de marcar esse diferente - vários colegas da escola, literalmente massacrados por seu modo "estranho" de vestir, de cortar ou pintar o cabelo, de caminhar etc. Incitados a falar sobre esses temas, a partir da exibição dos vídeos, meninos e meninas de 15 e 16 anos acabaram por manifestar-se parcialmente de acordo com a atitude da mãe de uma das personagens de Mulheres apaixonadas, que discriminava a relação homossexual da filha com a colega: "Bah, cara, já pensou? Meu filho chegar em casa e dizer pra mim que tá apaixonado por um cara? Não dá!".

Obviamente, o mesmo tema da relação homossexual conduziu a outros caminhos, na turma de alunos de uma escola de educação de jovens e adultos que atende estudantes de 14 a 80 anos, a maioria deles pobres, moradores de rua, trabalhadores, homens e mulheres atrasados nos estudos, pelos mais diferentes motivos. Num dos encontros, um jovem saiu por completo da novela e mergulhou em sua história pessoal, que incluía irmãos e primos homossexuais, em situação de miserável prostituição. De qualquer forma, nesses dois ambientes tão díspares, estava plantada a discriminação, também o desejo de não pertencer à condição de "anormalidade", que a novela trazia para o debate público, com todos os cuidados para não ferir uma sociedade que, hipocritamente, permitiu apenas um beijo ficcional entre as protagonistas, na última cena da novela.

A novela Malhação, discutida entusiasticamente pelo grupo de calouros de comunicação, serviu para que os jovens situassem a TV e a mídia de um modo geral como fonte de estímulo permanente da vivência sexual cada vez mais precoce e, paradoxalmente, como lugar de controle e vigilância desses mesmos atos incitados. Os estudantes mostravam ali o quanto Foucault (1992) estava correto quando afirmou, nos idos dos anos de 1970, o caráter complexo e dinâmico do dispositivo da sexualidade, que funcionaria não como controle-repressão, mas como controle-estimulação: incita-se a falar, a mostrar, a ver, a respirar corpos nus e sexualidade, a todo o momento; mas isso vem acompanhado de 
Mídia e juventude: experiências do público e do privado na cultura

uma série de normas, que vão se alterando conforme as resistências, os movimentos e as conquistas sociais, de homens e mulheres, adultos e jovens. Assim, se os corpos estão liberados a mostrar-se, a verdade é que eles deverão mostrar-se de um modo específico: lindos, magros e, mais recentemente, "sarados", com membros muito bem "definidos", "bombados", e assim por diante. Sim, que os jovens sejam livres para viver sua sexualidade, mas que falem tudo, por exemplo, para os pais; que vivam seus encontros amorosos com total liberdade, mas que obrigatoriamente usem camisinha.

Os exemplos são intermináveis, e os jovens universitários concluem: em Malhação, "incentivam e cobram isso de ti ao mesmo tempo, sabe?" (...) "Colocam um pai falando com a filha [dizendo] que é uma responsabilidade enorme [transar], que não sei o quê... A pessoa, assim, o jovem fica pressionado. Se ela levava aquilo naturalmente, mesmo que não comentasse com os pais (...), aí, vendo aquilo, fica [pensando]: 'Bah, mas eu tenho que falar com o meu pai! Tipo: ele deve saber". No debate, além de identificar o movimento permanente de controle-estimulação do dispositivo da sexualidade, o grupo remete a um outro dispositivo, o dispositivo pedagógico da mídia, pelo qual há que se construir esse lugar, dos meios de comunicação, como lugar predominantemente educativo. ${ }^{9}$ A observação de um dos estudantes vai direto ao ponto: para ele, criar uma cena como essa de Malhação, da menina pedindo licença ao pai para ter sua primeira relação sexual, "é pra Globo dar uma de boa moça, pras mães não pegarem e ficarem dizendo - 'meu filho tá vendo porcaria' (...). Mas pra mim isso é uma enganação".

Numa discussão especificamente sobre participação política dos jovens, acionada pela exibição de uma edição do programa Tome conta do Brasil, apresentado por Cazé, da MTV, no período eleitoral de 2003, os estudantes de comunicação mostraram o quanto em nossa sociedade se torna difícil separar política de politicagem, política de corrupção, telejornalismo de sensacionalismo. "Neguinho quer ver escândalo", diz um dos participantes; outro complementa: "Tu espera que a televisão mostre isso". Eles se dão conta do que lhes é ensinado: [nós aprendemos que] "o Estado é fraco e [que] isso é conseqüência dos políticos serem corruptos”. Também referem que a TV nos ensina a rejeitarmos determinadas figuras do meio político, por um detalhe de seu corpo, pela associação permanente destas com a corrupção, com a 
compra de votos. "Parece que isso [político é corrupto] tá enraizado na gente" - lamenta um dos alunos.

Mais uma vez, os conceitos de produção de verdade e de modos de subjetivação, aprendidos na obra de Foucault (1990; 1992), parecem tornar-se carne em tais depoimentos. A verdade é deste mundo, diz Michel Foucault, ela se faz história, nos corpos, nas práticas mínimas do cotidiano, é dessa forma que se disseminam e se reforçam os discursos, é dessa forma que operam as relações de poder. Os enunciados - como o de que política é coisa negativa, é coisa de gente que deseja roubar e enriquecer - são produzidos e divulgados, numa trama complexa de relações de poder e de saber. E passam a ser parte dos grupos, dos indivíduos, daqueles que de alguma forma se tornam então sujeitos dessas verdades. Porém, seguir Foucault e discutir a produção e a disseminação de verdades em nosso tempo significa igualmente mostrar os movimentos de resistência, as contraverdades que se produzem e que aparecem também nos programas de TV, também nos debates com os alunos.

Uma minissérie como Cidade dos homens, ${ }^{10}$ criada a partir do filme Cidade de Deus, permitiu que adolescentes de 15 e 16 anos, numa escola particular, debatessem seu sentimento de impotência diante da miséria e da pobreza, o quanto se sentem constrangidos, o quanto estão alimentados de medo com relação a esse outro que - eles têm consciência - até "pagam mais caro que nós pra ter as mesmas coisas que a gente consegue". (...) "Lá [nas vilas pobres da cidade] eles têm que batalhar pra conseguir comer e aqui [referindo-se a eles, de classe média] o cara ganha de graça, o cara passa quase o resto da vida comendo de graça...”. Lembram que as pessoas estranham existir um médico negro, um juiz negro, porque negros em geral são pobres e não cursam universidade, e um deles conclui, um tanto conformista: "Quando todo o mundo trabalhar no mesmo plano, quando tudo tiver igual, a gente vai conseguir olhar igual [para essas pessoas]. Agora não dá!”. Ainda sobre o episódio de Cidade dos homens, o debate encaminhou-se para pensar o medo e a violência, ao mesmo tempo o papel da mídia nesse quadro: "Hoje em dia tu desconfia de qualquer um que tu não conhece"; "quando tu abre a folha de um jornal, tu vê assim, ah, um roubo sensacional, um seqüestro sensacional. Aí o cara que lê [pensa]: 'Pô, o cara conseguiu sair no jornal, eu não vou conseguir sair no jornal...”.

Como é possível observar, o trabalho com os grupos de discussão propiciou uma série de achados, relativos não só à análise dos pro- 
Mídia e juventude: experiências do público e do privado na cultura

dutos da mídia, mas principalmente aos modos de recepção. Mais do que isso, a pesquisa acabou por mostrar que a escola é um lugar privilegiado para professores e alunos pensarem sobre esse tempo que estão vivendo; e que os debates a partir de produtos da mídia podem ser extremamente ricos, na medida em que as temáticas e as respectivas linguagens midiáticas, ao serem discutidas, expōem as contradiçōes que todos vivemos, põem o dedo nas feridas que estamos sofrendo; por fim, abrem espaço para que se produza pensamento, que se criem idéias para além do que parece estar "enraizado em nós".

\section{Narrações de vida como programa político}

Bauman propõe que fazer articulações entre narrações de vida narraçōes nossas, narraçōes da mídia, não importa - é algo que tem a ver com a tarefa de conferir sentido e finalidade à própria vida - e isso, em nossa sociedade, é não só uma tarefa e um direito individual, mas algo que pertence a todos, embora seja um direito difícil de reivindicar muitas vezes. Examinar narrações de vidas é trabalho necessário, urgente, e tem a ver com um programa político mais amplo, que inclui os interesses privados e o bem público. Se a esfera pública tem sido colonizada por interesses privados, sistematicamente podados e despojados de suas conexôes públicas e arranjados para o consumo privado e quase nunca para a produção de laços sociais, tal trabalho também pode ser pensado como uma "descolonização" da esfera pública. Estamos junto com Bauman, quando este sugere que se crie uma "nova ágora, vibrante e populosa, onde todos se encontrem, para traduzir em ambos os sentidos os idiomas dos interesses privados e o bem público" (Cf. Bauman, 2001, p. 24; tradução minha).

Penso que isso é não só possível como fundamental, num tempo em que somos insistentemente convidados, em programas como Big Brother e assemelhados, a recolhermo-nos à nossa intimidade, a partir de "fórmulas de autenticidade privada propagadas pela indústria cultural", como escreve Zizek (2003, p. 105). Para o crítico esloveno, o único caminho para romper com todas essas restriçóes à nossa subjetividade estimulada pela televisão, pelos jornais, pelas revistas, pelo cinema (particularmente o cinema hollywoodiano), pela publicidade, que nos convidam a uma privacidade totalmente objetificada - "é inventar uma nova coletividade", que nos permita sair do reduzido espaço do "eu e você que 
nos amamos", conduzindo-nos para o olhar que deseja ver o que se passa à nossa volta e engajar-nos em algum tipo de compromisso (idem, ibid.).

Para pensar uma nova coletividade, talvez seja necessário também produzir pensamento sobre os modos como estamos sendo narrados e os modos pelos quais estamos aprendendo a nos conectar conosco mesmos e com os outros. Se é verdade que nossas criações imaginárias existem para nos ajudar a lidar com o que não conseguimos compreender - a morte, por exemplo, e esse é o exemplo mais radical -, também é verdade que, num tempo como o nosso, em que tudo estaria coberto pelo imaginário, tudo seria imaginado para e por nós, "nenhuma mudança substancial parece possível” (Kehl, 2004, p. 12). Aí é que emergem os atos de intervenção diretamente no real (os ataques às torres gêmeas em Nova York são o exemplo mais radical disso).

Importa aqui sublinhar o quanto estudar imagens e narrativas oferecidas pela indústria cultural fortalece a proposta de operar sobre as cenas imaginárias das quais nosso pensamento está sendo presa; é preciso oferecer e criar alternativas para a interpretação dos fatos, para as narrativas que nos são oferecidas diariamente pelos meios de comunicação. Como escreve Maria Rita Kehl, "só no campo do simbólico tal mobilidade é possível” (idem, ibid.). Certamente, há que se intervir no real, já que as condições de milhões de crianças e jovens deste país, de homens e mulheres de todas as idades, precisam melhorar e com urgência, e isso deverá vir acompanhado de uma tarefa também urgente de ressimbolização, produzida por efeito dos próprios atos de intervenção. Para Zizek, todos os atos contêm riscos, não há garantias plenas.

Seguindo Zizek, Bauman, Hannah Arendt, Foucault, entendemos que é possível criar nas escolas situaçôes as mais variadas de problematizar o que nos acontece neste presente, a partir de trabalhos que tenham como ponto de partida a mídia e suas construções imaginárias sobre vida privada, vida pública, modos de ser adolescente, jovem, homem, mulher neste Brasil do século XXI. Se para Foucault a verdade é deste mundo, para Hannah Arendt a subjetividade e a identidade também são deste mundo, são acontecimentos históricos, não são preexistentes, justamente porque é na ação e no discurso que mostramos quem somos. Há que se distinguir as ações e os discursos que são mera conversa, simples meios para alcançar um fim, palavras e gestos mecânicos, previsíveis, daqueles atos e falas que se caracterizam propriamente como acontecimento, 
Mídia e juventude: experiências do público e do privado na cultura

como matéria inesperada, sem resultados mensuráveis nem imediatos (Arendt, 2000, p. 197 e ss.).

Essa abertura ao acontecimento, ao inesperado, talvez seja matéria em total falta nas práticas educacionais de nosso tempo. É disso que estamos falando quando propomos que a mídia e seus imaginários sejam trazidos para o espaço escolar, como forma de encorajar uma certa disponibilidade de vida, de saída de nossos esconderijos, não para entrarmos no mundo das celebridades e da fama midiática, mas para conviver com o outro, expressar-nos, agir, dividir o poder e, nessa condição, sermos também singularidades, como escreve Arendt em $A$ condição humana.

A prática com grupos de recepção, comentada neste texto, conduziu o grupo de pesquisa a pensar exatamente sobre isso: cada aluno, cada participante, ali, naqueles encontros, estava sendo colocado diante de um tipo de produção imaginária de seu tempo, sobre a sexualidade jovem, sobre os conflitos geracionais, sobre os modos de conceber a atividade política, sobre os preconceitos de classe, de etnia, de gênero, e pôde pensar sobre essa produção, na condição de alguém que não se vê obrigado a resultados imediatos a partir de suas intervençóes. $\mathrm{O}$ convite era simplesmente o de pensar sobre o modo como estamos sendo imaginados, construídos, nomeados, interpelados. Pensar sobre a complexidade desse mundo feito de imagens, mas que nos cobra diariamente um tipo de ação, de posicionamento, de gesto. $\mathrm{O}$ convite foi aceito pelos seis grupos pesquisados. É o mesmo convite que agora faço aos que me lêem e que atuam nas redes de ensino, ou que pesquisam no campo educacional: o convite de entregar-se a um trabalho cotidiano de debater a mídia no ambiente escolar, aceitando como ponto de partida que há uma tensão entre a ordem dominante, entre uma mídia que produz e veicula sentidos sobre modos de existência jovem, formas particulares de exercício da vida pública e da vida privada, e uma outra ordem, quem sabe?, uma desordem criativa, aquela referente ao agir humano de que nos fala Hannah Arendt, e que aposta na vida e na ação como acontecimento, como imprevisibilidade, como experimentaçóes do político nos amplos espaços da vida social.

Para concluir, volto a Bauman, que pautou todo este texto. Entendo, como o autor, que toda a energia que acumulamos, na busca de conferir sentidos às nossas vidas, é hoje, mais que nunca, espetacularmente apropriada pela televisão, pelo cinema, pelas revistas, pelos jornais, pelo mercado, enfim. Porém, essa mesma energia pode ser canali- 
zada adequadamente, pode produzir obras maravilhosas, como alguns programas de TV que descobrimos em nossas buscas, filmes, obras de arte, poemas, como os próprios encontros que fazemos para estudar essa mesma produção; tal energia pode tornar-se a matéria a partir da qual criaremos modos e formas de vida dignas, diferentes possibilidades de ampliar e diversificar o capital cultural de crianças, adolescentes e jovens neste país. Um caminho, aqui proposto, é o de apropriarmo-nos das produções midiáticas de imaginário, expondo-as ao debate, fazendo-as também criação e pensamento.

Recebido em fevereiro de 2005 e aprovado em março de 2005.

\section{Notas}

1. Trata-se da investigação "Mídia, juventude e reinvenção do espaço público", realizada de 2002 a 2004, com apoio do CNPq.

2. Ver Fischer, 1996; 2000a.

3. Os dois primeiros do SBT e o último da Rede Globo.

4. Sobre modos de analisar produtos da TV, ver Fischer, 2003.

5. Novela das oito, veiculada pela Rede Globo em 2003.

6. Exibido pela Rede Globo, de segunda a sábado, após o telejornal Hoje.

7. Foram selecionados seis grupos de recepção, alunos de ensino médio e universitários, de instituições públicas e privadas, em Porto Alegre (RS).

8. Telejornal veiculado diariamente, a partir das 13 horas, pela Rede Globo.

9. Trato do dispositivo pedagógico da mídia em vários textos; ver Fischer (2000b, 2002, 2003).

10. Utilizamos os quatro programas da minissérie, veiculados pela Rede Globo de 15 a 18 de outubro de 2002.

\section{Referências bibliográficas}

BAUMAN, Z. La sociedad individualizada. Barcelona: Catedra, 2002. BENTES, I. A sociedade contra a TV. Folha de S. Paulo, São Paulo, 05 out. 2003. Caderno Mais! p.4-5.

ARENDT, H. A condição humana. Rio de Janeiro: Forense Universitária, 2000. 
Mídia e juventude: experiências do público e do privado na cultura

DALLA ZEN, L. Do velho para o novo: sexualidade jovem em tempos de mídia. In: Salão de Iniciação Cientifica da Ufrgs, 15., 2003, Porto Alegre. Porto Alegre: PropesQ/ufrgs, 2003. (Texto digitado).

FOUCAULT, M. Microfísica do poder.Rio de Janeiro: Graal, 1992.

FOUCAULT, M. História da sexualidade I: a vontade de saber. Rio de Janeiro: Graal, 1990.

KEHL, M.R. Os excessos do imaginário. Folha de S. Paulo, São Paulo, 18 jan. 2004. Caderno Mais! p. 12.

FISCHER, R.M.B. Adolescência em discurso: mídia e produção de subjetividade. 1996. 297f. Tese (Doutorado) - Faculdade de Educação, Universidade Federal do Rio Grande do Sul, Porto Alegre.

FISCHER, R.M.B. Midia, juventude e reinvenção do espaço público. Porto Alegre: Ufrgs/CNPq, 2000a. Projeto de Pesquisa (texto digitado).

FISCHER, R.M.B. “Técnicas de si” na TV: a mídia se faz pedagógica. Educação, São Leopoldo, v. 4, n. 7, p. 111-139, jul./dez. 2000 b.

FISCHER, R.M.B. O dispositivo pedagógico da mídia: modos de educar na (e pela) TV. Educação \& Pesquisa, São Paulo, v. 28, n. 1, p. $151-162,2002$.

FISCHER, R.M.B. Televisão \& educação: fruir e pensar a TV. 2 ed. Belo Horizonte: Autêntica, 2003.

SONTAG, S. Diante da dor dos outros. São Paulo: Cia das Letras, 2003.

WESTPHALEN, F. Midia e juventude: aversão ou inversão política? In: Salão de Iniciação Cientifica, 15., 2003, Porto Alegre. Porto Alegre: PROPESQ/UFRGS, 2003. (Texto digitado).

ZIZEK, S. Bem-vindo ao deserto do real. São Paulo: Boitempo, 2003. 